\title{
A memória e a história a partir de museus e da constituição de arquivos em torno do espaço urbano ${ }^{1}$
}

\author{
Maria Cláudia Teixeira \\ Universidade Estadual do Centro-Oeste (UNICENTRO), Guarapuava, Paraná, Brasil \\ m_teixeira5@yahoo.com.br
}

DOI: http://dx.doi.org/10.21165/el.v46i3.1636

\begin{abstract}
Resumo
Pelo viés da Análise de Discurso, desenvolvida por Michel Pêcheux na França e pela consolidação da área a partir de Eni Orlandi no Brasil, elegemos o museu, como lugar de memória, que significa o sujeito e o espaço urbano, a partir de estudos de pesquisadores da área. Neste trabalho, problematizamos o lugar de museus na constituição de memórias e imaginários urbanos, tendo como centro o projeto desenvolvido na UNICENTRO/PR, intitulado "Museus e arquivos: lugares de memória do/no espaço urbano".
\end{abstract}

Palavras-chave: museu; discurso; memória.

Mémoire et histoire de musées et de la formation de dossiers dans le espace urbain

\section{Résumé}

Du point de vue de l'analyse du discours, développé par Michel Pêcheux en France et consolidé par Eni Orlandi au Brésil, nous avons choisi le musée comme un lieu de mémoire, ce qui donné signifié au sujet et à l'espace urbain, a partir des études de chercheurs. Dans ce travail, nous nous interrogeons sur la place des musées dans la constitution des mémoires urbaines et imaginaires, centrés dans le projet développé dans UNICENTRO / PR, intitulé «Museus e arquivos : lugares de memória do/no espaço urbano». [Les musées et les dossiers: Lieux de mémoire de/dans l'espace urbain].

Mots-clés: musée; discours; mémoire.

\section{O museu no mundo}

Na Análise de Discurso, o museu tem sido pouco trabalhado, especialmente, porque se trata de um objeto da História e da Arquivologia. No entanto, desde 2008, a partir da tese de Venturini (2008) e do livro que resultou dessa tese, em 2009, na Unicentro, temos desenvolvido projetos em torno desse objeto, destacando-se, o projeto de produtividade da pesquisadora, desenvolvido de 2014 a 2016, com apoio da Fundação Araucária e o projeto apoiado pela SETI (Secretaria de Ciência, Tecnologia e Ensino Superior). Pelo senso comum, o museu é significado como lugar que guarda tudo aquilo que se refere à memória de um povo, de um fato, de uma cultura,

\footnotetext{
${ }^{1}$ Este artigo resulta de discussões realizadas no Projeto de extensão intitulado "Museus, arquivos: lugares de memória no/do espaço urbano", coordenado pela Profa. Dr. Maria Cleci Venturini e desenvolvido em duas escolas, uma de Guarapuava (Escola estadual Manoel Ribas) e outra na cidade do Pinhão (Escola decisão Júnior). O projeto teve quatro bolsistas: Maria Cláudia Teixeira (orientadora), Paula Maryá Fernandes e Sandy Karine Lima dos Santos Semczesz (bolsistas recém-formadas) e Luciane Munhoz Stefano (bolsista de graduação).
} 
funcionando, portanto, como uma suspensão do/no tempo, congelando neste espaço todas as coisas que foram importantes em determinado tempo da história para que esta possa ser conhecida pelo sujeito e vivenciada por meio daquilo que é mostrado/exposto em diferentes objetos.

Tratar-se-ia de um lugar que acondiciona coisas antigas. Não podemos dizer todas, pois o tudo não pode ser abarcado. Essa memória é gerenciada, organizada por instituições ou por sujeitos que se filiam a elas e, de acordo com Venturini (2009, p. 34), fazem circular sentidos institucionalizados "pelo funcionamento da memória e realiza-se pelas coerções sociais imputadas a grupos", em nosso texto, os sujeitoscidadãos da cidade de Pinhão. O museu é um espaço ilusoriamente tomado como completo, pleno, absoluto, total, inteiro e concluso, como se toda a história estivesse ali contida e toda ela fosse pautada na verdade, na precisão e na exatidão e fosse, ainda, imaginariamente real, tangível e verídica. Acima de tudo, inquestionável e certa. Seria, então, um lugar que "guarda" tudo que deve/pode ser rememorado e que se constitui como o que deve ser lembrado, como materialidade para não ser esquecida, cujo objetivo é a preservação da memória pela história.

Neste espaço imaginado de permanência no/do tempo, funciona uma memória pela qual se constrói uma história para e pelo sujeito, via pela qual inscrevemos nossa problematização: como a memória se constitui e entra em funcionamento no museu? Tomamos como objeto de análise o Museu Histórico da cidade de Pinhão, no Paraná, e também comentários referentes ao texto intitulado "Grandes lembranças de uma pequena localidade", publicação digital de $2013^{2}$. Trata-se de um texto de rememoração/comemoração do espaço urbano, que retoma acontecimentos passados do povoado denominado Zattarlândia, pertencente ao município de Pinhão, PR. Esta localidade foi assim chamada devido à grande empresa madeireira João José Zattar, instalada na década de 1940. Junto ao texto seguem-se vários comentários/relatos que analisaremos tendo como fundamentação teórica a Análise de Discurso de linha francesa.

\section{O percurso teórico}

Percorrer uma trilha teórico-metodológica requer que a conheçamos, assim, não nos perderemos no caminho, mobilizando conceitos, que ajudam na tessitura do discurso analítico. A Análise de Discurso (doravante AD) foi fundada na década de 60, pelo filósofo francês Michel Pêcheux, e tomou novos rumos a partir dos direcionamentos empreendidos pela analista de discurso brasileira Eni Orlandi e uma série de pesquisadores depois dela, que tomam a $\mathrm{AD}$ como alicerce teórico. Esta teoria trata especificamente do discurso, seu objeto de estudo, analisando-o em textos, não só os escritos, mas qualquer manifestação de linguagem, tomada como ponto de partida para se verificar o seu funcionamento. O discurso é definido por Pêcheux, em Análise Automática do Discurso (1969), como efeito de sentidos entre interlocutores, ou seja, o sentido está na relação entre os sujeitos simbólicos dentro de determinadas circunstâncias e não nas palavras, que sozinhas não significam. Para a AD todo dizer constitui-se como efeitos de sentidos, produzidos em condições determinadas e que de

\footnotetext{
${ }^{2} \mathrm{O}$ texto intitulado "Grandes lembranças de uma pequena localidade" está disponível no endereço: $<\mathrm{http}$ //sites.unicentro.br/jornalagora/grandes-lembrancas-de-uma-pequena-localidade/>.
} 
alguma forma estão presentes no modo como se diz.

Essas condições determinadas denominam-se "condições de produção" e são compreendidas a partir de dois contextos: o estrito e o amplo. No contexto estrito, remetem às condições de enunciação, ao contexto imediato, ao observável, abrangendo os sujeitos e a situação, enquanto que, em sentido amplo, as condições de produção incluem o contexto sócio-histórico e ideológico. Ou seja, as condições de produção não se restringem aos fatores imediatos ou apenas ao contexto sócio-histórico, mas também ao imaginário, ao já-dito, à memória. Falar em condições de produção é levar em conta todos os fatores de construção do discurso: quem diz, o quê, para quem, como, por que, como são postos em circulação os já-ditos e a memória, que retornam e dão sustentação ao dizer como discurso.

Esta memória de que trata a $\mathrm{AD}$ e que também faz parte das condições de produção, não é a memória psicologizante, como aquela que guardamos em álbuns e acessamos sempre que queremos, ou aquela que se encontra estática no museu e pode ser visitada; trata-se da memória do dizer ou do interdiscurso. De acordo com Orlandi (2005), o interdiscurso pode ser definido como um conjunto de formulações perpetradas, que de certa forma foram esquecidas, mas definem o que o sujeito articula. Segundo Orlandi (2005, p. 32), todo o dizer é sustentado por um já-dito, ou seja, todo o dito, todo o discurso linearizado, só faz sentido porque há um já-dito "que sustenta a possibilidade mesma de todo dizer" e este já-dito "é fundamental para se compreender o funcionamento do discurso, a sua reação com os sujeitos e com a ideologia". O interdiscurso encaminha o dizer a toda uma filiação de dizeres, a uma memória. Para tratar do museu e a memória que funciona nele, Venturini $(2009$, p. 40) elegeu o museu como lugar de memória e iniciou as reflexões dessa noção a partir de Nora (1984), mas deslocou-o, definindo-o "como dispositivo que organiza a repetição e as lembranças do passado". Essa noção é bastante produtiva para se pensar no museu e no que não está nele, mas nos sujeitos que viveram os acontecimentos da Zattarlândia.

Para trabalhar com o museu, Venturini (2009) pensou a memória constituída pela rememoração/comemoração, em que um discurso de constitui a possibilidade de o discurso sobre funcionar, circular e organizar o que deve/pode ser lembrado e, de certa forma, o que estará no museu. Nesse sentido, a rememoração é significado como espaço discursivo que se constitui pela memória discursiva e dá visibilidade a sujeitos, a partir de formações discursivas. O sujeito como quem organiza ou visita o museu participa desse desejo de manter vivo o passado, suscitando a comemoração. Segundo Venturini (2009, p. 49):

[...] assim, constitui os andaimes que estruturam o discurso comemorativo, no qual se materializam os gestos de comemoração, como o "fazer memória" pela institucionalização e pela legitimação da celebração de nomes ou eventos significativos para uma formação social. [...] Alguns desses andaimes são retirados da obra (museus) e, por vezes apagados, mas retornam ao eixo da formulação porque são imprescindíveis para a atualização da memória.

Para pensar o discurso que funciona no lugar de memória e mobilizar a noção rememoração/comemoração, Venturini (2009) ancorou-se em Pêcheux (1997) e Courtine (1999). Para o primeiro, todo dizer é sustentado por um já-dito, que foi esquecido, mas retorna e produz sentido, tendo em vista que o dizer não é saturado; pelo contrário, é todo vazado e cheio de falhas. Já para o segundo, o discurso constitui-se por 
meio de dois eixos: o vertical e o horizontal, sinalizando para o interdiscurso e para o intradiscurso. Nesse sentido, o eixo vertical abarca a constituição, a memória, enfim, o interdiscurso e o eixo horizontal, o dizer em sua linearidade, o discurso. Nas falhas é que o eixo horizontal é atravessado pelo eixo vertical - da constituição - o interdiscurso.

Venturini (2009, p. 101) esquematizou esse funcionamento da memória e trata a rememoração como discurso de e a comemoração como discurso sobre. Nesse sentido, a rememoração funciona no eixo paradigmático, que é a dimensão não-linear do dizer (o interdiscurso), no lugar do já-dito, estabilizado e constituído pelas repetições, dadas pelos processos parafrásticos. A comemoração, então, funciona no eixo sintagmático, na dimensão linear do dizer (o interdiscurso) e é nesse espaço, na tensão entre o já-dito e o dito na formulação que o dizer se reformula e reinscreve o dizer no interdiscurso. Com isso, segundo a autora, constitui-se o efeito de memória, a possibilidade do novo, o processo polissêmico, nos termos de Orlandi (2005). O processo parafrástico e o processo polissêmico constituem a rememoração/comemoração, pela impossibilidade de separar o que é a memória e o que é a atualidade. Nesse esquema, observa-se que o discurso se constitui pela memória discursiva, espaço em que se juntam o discurso de e o discurso sobre, de acordo com Venturini (2017, no prelo). Pêcheux (1999, p. 52), assinala que:

[...] a memória discursiva seria aquilo que, face a um texto que surge como acontecimento a ser lido, vem restabelecer os 'implícitos' (quer dizer, mais tecnicamente, os pré-construídos, elementos citados e relatados, discursos-transversos, etc.) de que sua leitura necessita: a condição do legível em relação ao próprio legível.

Podemos assim dizer que a memória discursiva pode ser considerada como um efeito da presença do interdiscurso, como algo que já foi falado antes, está sendo falado, e a fala surge de um espaço independente. De acordo com Orlandi (2005, p. 34), o interdiscurso provoca um efeito de esquecimento, pois "é preciso que o que foi dito por um sujeito específico, em um momento particular se apague na memória para que, passando para o 'anonimato', possa fazer sentido em minhas palavras". Pelo efeito de esquecimento, conforme teorizações de Pechêux (1997 [1975]) e Orlandi (2005), o sujeito tem a ilusão de ser a origem do dizer e que o seu dizer só pode ser dito do modo como diz, esquecendo-se que a língua não é transparente e sempre desliza para outros sentidos.

Pautamo-nos nessas considerações teóricas e pelos conceitos pontuados que entendemos e analisamos o Museu Histórico de Pinhão e os comentários/relatos tomados como corpus.

\section{O olhar discursivo sobre o Museu}

Ao tratar de museus, inevitavelmente, enfocam-se e se discutem os conceitos de patrimônio e de arquivo, pois eles instauram redes que resultam na construção de efeitos de sentidos sobre a memória e sobre a história, tidas ilusoriamente como completas e transparentes, do que resultam efeitos de completude e de certitude. Pelo viés discursivo, no qual nos inscrevemos, a memória não se refere às lembranças vividas, individuais e subjetivas, mas a discursividades que "trabalham" para desestabilizar os discursos, os quais, pelo funcionamento do antagonismo e do contraditório, são 
constantemente reformulados e transformados. É assim que o discurso de funciona como memória, como o que se repete e instaura processos parafrásticos, em que o dizer é retomado e constitui redes de memória. Para Orlandi (2005, p. 31), a memória discursiva refere-se "[ao] saber discursivo que torna possível todo dizer e que retorna sobre a forma do pré-construído, o já-dito que está na base do dizível, sustentando cada tomada de palavra”.

$\mathrm{O}$ encontro entre o discurso de, como rememoração e o discurso sobre como comemoração ocorre pela memória discursiva como base de todo dizer, pois é o já-dito, enquanto discurso de, que sustenta o dizer e faculta. Nessa perspectiva, a memória não é apenas um fio invisível e imaginário que liga passado e presente e que pode ser acionada como lembranças sempre que se queira. Ela é constitutiva de sujeitos e dos seus discursos porque nela se atravessa e ressoa a materialidade discursiva, como um saber discursivo, portanto, social, coletivo e globalizante.

A rememoração funciona como memória, como um discurso de, pelo qual retornam discursos passados, inscritos em outros períodos da história. Trata-se daquilo que já foi dito antes em outro lugar, e agora é (re)-significado. Conforme Venturini (2009, p. 73), "a rememoração ocorre na dimensão não linear do dizer e ocupa o espaço do já dito e do significado antes, em outro lugar, cujo retorno ocorre pela repetição, que de um lado, estabiliza os sentidos e, de outro, instaura o novo". A comemoração se constitui a partir da rememoração, e enquanto este se refere ao discurso de, a primeira, a comemoração, tem como contraparte o discurso sobre, "que funciona como a memória que o constitui e como discurso fundante que retorna e o ancora no eixo da formulação" (VENTURINI, 2009, p. 75). Desse modo, o discurso (como memória) se constitui e se materializa a partir da memória, que funciona por meio de dois eixos: o das relações $-\mathrm{o}$ intradiscurso - e o das seleções - o interdiscurso.

Contrariamente ao que circula pelo senso comum, o museu funciona como "lugar de memória", porque nele, de acordo com Venturini (2009, p. 66), "se organizam e se repetem traços de identificação existentes entre os sujeitos do espaço de rememoração/comemoração e o objeto de comemoração". Desse modo, o museu é um lugar de memória e Venturini (idem, p. 67) destaca que esse lugar funciona como arquivo, "porque é em si mesmo um documento, não como mobiliário material, mas como objeto cultural que representa em si mesmo os conteúdos dos imaginários constitutivos dos objetos que arquiva". Conforme Bernardim (2013), o lugar de memória é também o lugar em que se realizam gestos de interpretação. Desse lugar emerge uma gama variada de discursos, produzindo diferentes efeitos de sentido. $\mathrm{O}$ lugar de memória ocorre, de acordo com Venturini (2009, p. 66), "pela inscrição do lugar na ordem do simbólico e faz retornar enunciados já-ditos, significados, mas esquecidos". Assim, o lugar de memória produz efeitos de permanência do tempo.

Venturini (2009, p. 70) diz também que o lugar de memória possui duplo papel: impede o esquecimento de antigas tradições, e promove o resgate de laços de continuidade, assegurando a permanência do tempo tridimensional, que abarca três tempos: o passado, pelo qual se interpreta o presente e o futuro como possibilidade, que alia passado e presente. Assim, assegura a conservação (mesmo ilusoriamente) e o gerenciamento das memórias, a transmissão de valores institucionais e funciona como um organizador que sustenta a continuidade e/ou ruptura dos discursos. 
É neste ponto que o conceito de memória discursiva funciona no museu, pois este, como lugar de memória, ao arquivar e organizar a memória social e coletiva promove a permanência do tempo tridimensional e oferece espaço para a produção de diferentes efeitos de sentido, diferentes gestos de interpretação e de diferentes discursos. Ainda de acordo com Venturini (2009, p. 92):

[...] a escolha do que faz parte da memória e o que é silenciado está a cargo das instituições, como legitimadoras da memória, as quais buscam determinar o que deve ser lembrado e o que deve ser esquecido, num movimento dialético em que a lembrança pressupõe o esquecimento no discurso de comemoração. No entanto, ao se inscreverem no espaço discursivo, os sentidos deslizam, rompem com a linearidade.

É nesse funcionamento que no museu, como "lugar de memória", apesar do trabalho da ideologia no efeito de naturalização das instituições que determinam o deve/pode ser esquecido ou lembrado, visibilizado ou silenciado, ocorrem deslizamentos pela repetição. No espaço urbano, nesse texto, a cidade do Pinhão, o museu, segundo Venturini (2009, p. 187), "é o lugar de acontecimentos discursivos que encaminham para lugares". Esses lugares organizam as memórias e os saberes, mesmo assim, a partir deles ressoam memórias e discursos que vêm de outros lugares, retornam e se atravessam, pelo que Pêcheux (1997) chama de discurso transverso.

Os sujeitos responsáveis por esses espaços realizam gestos de interpretação na organização do arquivo. No espaço urbano, esse sujeito é o sujeito porta-voz e no museu, ao selecionar certos arquivos, deixa de lado uma série de outros, porque o museu não pode abarcar tudo. Neste movimento de seleção e de escolhas se produzem efeitos de sentidos e retornam discursos e memórias, enquanto outras são silenciadas. $\mathrm{O}$ museu não pode abarcar a memória em seu todo, mas apenas vestígios dela, mesmo que se sustente na ilusão de que este lugar de memória é completo e fechado a interpretações. É pelo gesto de seleção que se determina, mesmo que inconscientemente, a ruptura ou continuidade do discurso em torno da história e da memória. De acordo com Venturini (2009, p. 69):

[...] as visibilidades e os apagamentos efetivados não são da mesma ordem, visto que cada instituição, apesar de ter o mesmo objeto discursivo, funciona diferentemente: os sujeitos investidos da posição de locutores ocupam diferentes posições-sujeito e são afetados por formações discursivas heterogêneas. A memória que as constitui e a emergência da formação social faculta a transformação de um lugar material em lugar de memória pelo arquivo. Há um processo seletivo de constituição do arquivo, que evidencia ou silencia e apaga fatos, de acordo com a inscrição do sujeito responsável pelo dizer, a uma ou outra formação discursiva que invade a formação discursiva da rememoração/comemoração.

Deste modo, ainda de acordo com Venturini (2009, p. 69), a função do museu, como lugar de memória, é "constituir, sustentar e interpretar sujeitos idealizados". O museu funciona como lugar de preservação do patrimônio cultural e coletivo e representa a identidade de um povo, de uma cultura, de um grupo. Deste modo, os museus têm como função a preservação e a comemoração da memória dos antepassados, valorizando e significando tal memória, representando, desta forma, a identidade de um grupo. 


\section{O Museu histórico de Pinhão}

Os efeitos de sentidos em torno desse museu têm início pela designação "histórico", que faz com que ressoem efeitos de veracidade, já que a História trabalha com fatos que podem ser comprovados e que são passíveis de comprovação por meio de documentos. Na verdade, esse museu possui e outros museus apresentam versões de uma história e pela quantidade de peças, de documentos, de enredos e de tramas, o discurso parece saturado, fechado e, mais do que tudo, centrado na isenção. Discursivamente, não importam os conteúdos, mas os modos como se constituem efeitos de história, de verdade, de saturação.

$\mathrm{Na}$ perspectiva discursiva, o museu como o lugar que significa não os dados históricos, mas os fatos da história e que tem um sujeito que organiza aquilo que será ou não visibilizado, é plausível dizer que aquilo que não está no museu também produz significados. Isso ocorre pela ausência, pois, segundo Courtine (1999), a ausência significa, muitas vezes, mais do que a presença, por não estar lá, por estar ausente, invisível, silenciado. Ao selecionar o que será exposto, deixa-se de lado o que será ocultado e o oculto também pede sentidos.

Para darmos visibilidade ao que significa pela ausência, recortamos para fins de análise o Museu Histórico do município de Pinhão, projeto e fundação que teve início com a própria comunidade, mais especificamente, por meio do projeto "Semeando a História de Pinhão", desenvolvido pelas professoras da rede estadual de ensino, Elizabeth Kramer e Maria da Graça Bosquirolli Argenta, que, preocupadas com a falta de um espaço próprio para a preservação da história e da cultura da cidade, apresentaram o projeto ao prefeito e tiveram sua aprovação em 2005. A organização do museu, segundo a professora Maria da Graça ${ }^{3}$, começou de forma lenta, pois não havia nenhum tipo de acervo. Assim, segundo conta a professora, os objetos que fazem parte do acervo hoje, foram conseguidos por meio de doações, empréstimos temporários e estão organizados em torno do livro tomo, no qual estão registrados todos os objetos recebidos.

O Museu Histórico de Pinhão está disposto em salas temáticas não havendo um destaque único, a história do município está no conjunto dos objetos, livros e documentos expostos. As exposições são feitas não apenas no espaço interno do museu, mas também no externo, no qual está exposta a tecnologia do passado como as máquinas de moer, por exemplo, e os meios de transporte utilizados na época de formação da cidade.

Este museu é parte essencial da história de Pinhão, ele conta sobre o passado, mostrando o que permaneceu e o que se transformou com o tempo. Além disso, como destaca Maria da Graça, pretende trazer contribuição cultural, pois além de expor no espaço fixo, também apresenta e organiza exposições em eventos da cidade e de outros centros, levando a história da cidade para além das paredes museológicas.

\footnotetext{
3 No documentário "Museus, Arquivos: Lugares de Memória do Espaço Urbano". Disponível em: $<$ https://www.youtube.com/watch?v=u3ZR1kcxriM>. Acesso em: 10 jun. 2017.
} 
Apenas para título de contextualização, a cidade de Pinhão possui em torno de 30 mil habitantes e tem sua economia voltada para agropecuária, a agricultura e a indústria extrativista madeireira. É um município relativamente novo, fundado em $15 \mathrm{de}$ dezembro de 1964.

O município de Pinhão é destacado, nas narrativas de seus habitantes, como terra onde um dia houve madeira em abundância e lugar de bastante violência. Rodeado por grandes florestas de araucária e imbuia, o município é palco de um conflito de terras iniciado no final da década de 1940, quando as Indústrias João José Zattar S/A se instalaram no local. Sua intervenção sobre o território de Pinhão foi bastante intensa, já que não só obteve um terço da área total do município, como fechou com portões o acesso a bairros da zona rural, num espaço que a firma chamou de Zattarlândia, reduto particular da empresa e de seus empregados (AYOUB, 2010, p. 02).

A história desta indústria madeireira teve um impacto muito grande sobre a história da cidade de Pinhão. A indústria criou para si um espaço particular de habitação dentro do espaço reconhecido oficialmente como urbano. Um espaço próprio, particular, que chegou, inclusive, a ter suas próprias regras, sua própria moeda, como apontam relatos:

Minha família toda é de lá, meus avós foram os primeiros moradores do Zattar, lá era "escravidão disfarçada", pagavam os funcionários com um dinheiro criado por eles para que os mesmos só pudessem comprar no armazém e no açougue deles, ou seja, o dinheiro voltava todinho para eles. Aliás, os pobres nunca podiam comprar carne, só osso e bucho, porque a carne era vendida primeiro para os gerentes e o que sobrasse os pobres podiam comprar. As famílias se endividavam e nunca mais podiam sair do lugar, os filhos tinham que começar a trabalhar com 9,11 anos para ajudar em casa e ajudar a pagar dívida.

As famílias passavam fome, necessidade em tudo, ninguém tinha roupa, calçado, coberta para se aquecer no inverno que era muito rigoroso.

O gerente de lá, que todo mundo sabe quem é, maltratava as pessoas, adultos e crianças, faziam a todos de escravos particulares. Não falo só por histórias que eu ouço, eu vivi lá, sei muito bem que tratamento era dado, éramos tratados como animais.

Graças a Deus em 1995 saímos daquele lugar e como a justiça divina chega uma hora, aquele lugar está se acabando, pois que acabe mesmo e que essas pessoas paguem por tudo de ruim que fizeram ${ }^{4}$.

As sequências destacadas encaminham para o efeito de sentido de que o poderio da empresa, não só como espaço provedor do trabalho, mas principalmente como espaço fechado e regrado autoriza-a a ditar regras e a impor os seus modos de organização. Por meio deste relato, pode-se afirmar que o poderio funcionou como um aparelho de repressão, pois limitou a liberdade dos sujeitos, no aspecto financeiro, ao fixar moeda própria e demarcar limites territoriais, no que tange à segurança, ao ter seus próprios justiceiros. Como analistas de discursos, nossa função neste trabalho não se apega, de forma alguma, à defesa ou à acusação. Buscamos mostrar, por meio do

\footnotetext{
${ }^{4}$ Relato transcrito disponibilizado no site: $<\mathrm{http}$ ///sites.unicentro.br/jornalagora/grandes-lembrancas-deuma-pequena-localidade/>.
} 
funcionamento do discurso, como esta historicidade foi significada para e por diferentes sujeitos e, ao mesmo tempo, polemizar o silenciamento dessa empresa e das práticas realizadas por ela no museu.

O sujeito-locutor ou aquele que se responsabiliza pelo dizer, nesse discurso, pelo modo como diz, constitui efeitos não só de sentimentalismo, mas para os modos de organização de trabalho e do urbano, em que há o dominador e o dominado, significando a existência de uma relação de senhor e de escravo. Na formação social marcada pelo capital, haveria patrão e empregado, mas a exploração e a coerção fazem com que ressoe não só uma memória, mas pondo em funcionamento toda uma ideologia de classes, não do rico e do pobre, mas do patrão, gerente e do empregado dominado e explorado. Do gerente que assume o discurso do patrão e age como o dominador, esquecendo-se que também é um funcionário. Entretanto, como bom sujeito, repete e reproduz não só os atos, como também o discurso do patrão. Entendemos que há, nesse sentido, o funcionamento do bom sujeito, segundo Pêcheux (1997) em que o sujeito e a forma sujeito se sobrepõem.

O sujeito responsável por este discurso enfatiza a sua versão ao afirmar: "Não falo só por histórias que eu ouço, eu vivi lá, sei muito bem que tratamento era dado, éramos tratados como animais". Com essa ênfase, ele legitima o seu dizer e constitui efeitos de testemunho, podendo-se dizer que o efeito de veracidade é bem maior quando o sujeito afirma que viveu e não que contaram a ele. Segundo esse testemunho, o empregado, o funcionário, a engrenagem de funcionamento da empresa, aproximava os trabalhadores a animais. Com essa afirmação constituem-se redes metafóricas entre homem e animal, fazendo com que pela memória do que seja um e do que seja o outro, o tratamento dispensado aos empregados pela empresa.

A visibilidade para a relação entre patrão e empregados legitima-se e se ancora em discursos anteriores, que se sustentam na resistência, na denúncia da exploração e do desejo de lucro, em que o sujeito dominado é explorado. O discurso de, que ancora e ressoa na comparação do empregado como animal, sustenta-se em outros discursos, podendo ressoar, dependendo do sujeito que interpreta esse discurso, a escravidão, na qual as pessoas valiam tanto quanto um cachorro ou outro animal qualquer: irracionais, valorizadas única e exclusivamente pela força ou pela função desempenhada, ou seja, substituíveis. Por fim, o discurso religioso atravessa todo o fio discursivo e surge como discurso de vingança, o que instaura uma contradição: dar graças a Deus pelo castigo do outro. Como se pode ler na sequência abaixo:

Olá gostaria de acrescentar uma ressalva, antigamente eles mandavam matar pessoas para tomar posse dos terrenos de pessoas humildes e que também as coisas por lá se resolviam só na base da bala, isso é as pessoas mais velhas que moravam lá contam, adiantou tomar terra e agora perder tudo para os bancos, bem feito.

hoje vc tira de alguém, amanhã alguém tira de vc. ${ }^{5}$

As histórias de violência ainda atravessam o discurso do pinhãoense e sobre o pinhãoense, significando Pinhão como o lugar dos pistoleiros, dos jagunços, de assassinos. Sempre num tom de humor - "cuidado com ele, pois é do Pinhão" - revela,

\footnotetext{
${ }^{5}$ Relato transcrito do site: $<$ http://sites.unicentro.br/jornalagora/grandes-lembrancas-de-uma-pequenalocalidade/>.
} 
pelo atravessamento da memória no fio do discurso, a história do povo. Uma história ocultada pelo museu histórico da cidade. Uma história de violência que sempre está presente e que se põe presente justamente por estar ausente. Uma história para não ser comemorada, tampouco rememorada.

Por meio desses dois enunciados, em forma de relato, pode-se compreender que o sujeito porta-voz do museu silencia e apaga do museu essa parte da história, constitutiva do espaço urbano, por representar uma história de violência, uma história que ainda identifica o espaço, mas que não merece ser comemorada. Ocorre aí a simulação de uma naturalidade, mais precisamente, a idealização do lugar e da história. O que fica visível são os apagamentos, os silêncios que gritam por meio dos sujeitos que falam, que fazem memória.

Ocorre, portanto a desidentificação entre o sujeito porta-voz e a empresa. A formação discursiva do sujeito porta-voz do museu distancia-se da formação discursiva da empresa madeireira e, com isso, promove a ruptura no discurso da formação social do lugar. Pelo apagamento desta história no museu, rompe-se a memória que encaminha para a veracidade. A memória que está no museu produz efeitos de apagamento e de silenciamento. Assim, a memória tornada visível pelo sujeito porta-voz do museu, sujeito que organiza o lugar de memória e seleciona o arquivo, é a memória do herói e do vencedor, tirando deste lugar aquilo que é significado como tirânico, violento e sofredor, pondo em funcionamento a memória da luta, da conquista e do que representa a alegria.

\section{Considerações finais}

As considerações finais nunca são finais, ainda mais na perspectiva discursiva, em que se buscam os efeitos de sentidos e os processos que constituem esses efeitos, em detrimento dos conteúdos ou dos julgamentos. Diante disso, buscamos pensar no que não está no museu e que efeitos constituem o fato do funcionamento de uma vila, na qual o dinheiro é próprio desse lugar e os sujeitos que compõem o corpo de funcionários são comparados a animais, o efeito que se vê aí é que o Museu Histórico seleciona uma parte da História e silencia outra.

Os arquivos são higienizados, por assim dizer, não contemplam as práticas sociais, a vida se fazendo, mas somente uma parte da vida já feita. Trata-se de um falseamento dos acontecimentos. No entanto, vale sinalizar que a dominação e a presença da empresa ressoam na formação social e o não aparecimento dela no Museu, que se designa histórico, produz efeitos porque por essa ausência atravessam-se discursos advindos de outros domínios de memória.

A violência urbana e a violência contra os mais humildes não estão nos arquivos e nem na história que está no Museu, mas ressoam como constitutivas do espaço urbano. Ressoa também o fato de que as instituições que gerenciam as memórias e a história que está no Museu não permitem que sejam visibilizadas essas práticas. O fato de o museu não contemplar a parte triste da formação social não significa que ele seja o lugar da comemoração, ainda mais que essa noção recobre o funcionamento da memória na atualidade e não a celebração.

O que Venturini (2009) chama de rememoração não é a recordação, mas a memória funcionando como interdiscurso, sustentando e legitimando a comemoração, 
que é o discurso sobre, mais precisamente, a linearização do dizer, enfim o discurso em sua formulação. Então, voltando ao Museu, enquanto espaço discursivo se pode concluir que ele é um espaço e nele há um discurso e esse é o discurso sobre porque é atualidade, porque é discurso, tendo em vista que há interlocução entre sujeitos e, por isso, há também, efeitos de sentidos.

A prática de mostrar somente o lado bom da história e de apagar a parte menos boa é recorrente e faz com que os Museus trabalhem para a falsificação da história ou como o lugar da legitimação de uma determinada versão da história. O Museu passa a ser o lugar em que apenas a parte boa da História é mostrada e que somente isso vale a pena ser lembrado, conhecido, estudado em detrimento dos porões da história. Sendo desta forma, o museu ou o sujeito que organiza os arquivos, em seu gesto interpretativo, contribui para que a memória que entra no museu e lá permaneça seja sempre a história do vencedor, a visão do momento feliz, das conquistas. Tudo que não se enquadra neste modelo é "jogado para debaixo do tapete”, esquecido, apagado, ocultado.

Concluindo, pode-se dizer que o Museu não é o lugar da verdade e nem pode ser tomado como tal, pois os sujeitos não vivem somente de vitórias e de conquistas, mas também nas derrotas. Além do mais, o lugar de vencedor e o de perdedor depende das condições de produção, o que mostra que toda seleção de arquivo feita pelo sujeito ocorre pela identificação desse sujeito com uma determinada versão da história. Não se pode desconsiderar que essa identificação ocorre pelas condições de produção, da formação discursiva e da posição que o sujeito ocupa. Não se trata de mera seleção neutra, nunca será, pois toda escolha elege um em detrimento do outro, sem esquecer que uma escolha é feita através da ideologia. Deste modo, podemos afirmar que o museu reconta a história que lhe pareça ideal, reinventando o real e daí produzindo sentidos. É preciso que se questione para que se compreenda.

\section{REFERÊNCIAS}

AYOUB, D. S. Madeira sem lei: memórias de um conflito fundiário no Paraná. $34^{\circ}$ Encontro Anual da ANPOCS. Porto Alegre: 2010.

BERNARDIM, A. C. Colônias suábias em Guarapuava e o efeito discursivo da memória no espaço de imigração: entre a "Velha" e a "Nova" Pátria. 2013. $132 \mathrm{f}$. Dissertação (Mestrado em Letras) - Universidade Estadual do Centro-Oeste, Guarapuava, Paraná, 2013.

COURTINE, J.-J. Chapéu de Clementis. Observações sobre a memória e o esquecimento na enunciação do discurso político. Tradução de Freda Indursky. In: INDURSKY, F.; FERREIRA, M. C. L. (Org.). Os múltiplos territórios da análise do discurso. Porto Alegre: Sagra/Luzzato, 1999.

NORA, P. Entre mémoire et histoire. La problématique des lieux. In: Les lieux de mémoire. v. I. Paris: Gallimard, 1984.

ORLANDI, E. P. Análise do discurso: princípios e procedimentos. 6. ed. Campinas: Pontes, 2005.

PÊCHEUX, M. Semântica e discurso: uma crítica à afirmação do óbvio. Tradução de Eni P. Orlandi et al. 3. ed. Campinas: Editora da UNICAMP, 1997 [1975]. 
VENTURINI, M. C. Imaginário urbano: espaço de rememoração/comemoração. Passo Fundo: Editora da Universidade de Passo Fundo, 2009.

Recebido em: 30/08/2016

Aprovado em: 21/06/2017 